\title{
Polioencefalomalacia em bovinos nos estados de Mato Grosso do Sul e São Paulo ${ }^{1}$
}

\author{
Luciano Nakazato ${ }^{2}$, Ricardo A. A. Lemos ${ }^{3}$ e Franklin Riet-Correa ${ }^{4}$
}

\begin{abstract}
Nakano L., Lemos R.A.A. \& Riet-Correa F. 2000. [Polioencephalomalacia in cattle in the states of Mato Grosso do Sul and São Paulo.] Polioencefalomalacia em bovinos nos estados de Mato Grosso do Sul e São Paulo. Pesquisa Veterinária Brasileira 20(3):119-125. Depto Patologia, Fac. Veterinária, Universidade Federal de Pelotas, 96010-900 Pelotas, RS, Brazil.

Thirty outbreaks of polioencephalomalacia (PEM) were diagnosed from August 1993 to October 1997. Twenty nine occurred in the state of Mato Grosso do Sul and one in São Paulo. The disease affected cattle from 4 months to 7 years of age. Morbidity rates ranged from $0.02 \%$ to $14.28 \%$ and case fatalities from $42.5 \%$ to $100 \%$. The disease was not seasonal. All outbreaks occurred in cattle grazing Brachiaria spp, except one affecting feedlot cattle. Only neurologic signs were observed, and the course of the disease varied from 12 hours to 4 days in untreated cattle. Most animals treated with thiamine and dexamethazone recovered. Moderate cerebral edema was observed at necropsy. Cell changes were characterized by laminar necrosis and gitter cells. In two cases moderate cortical and submeningeal hemorrhages were observed. Nine cases had perivascular and submeningeal infiltrations by eosinophils. Sodium ion concentration of the cerebrospinal fluid was elevated in one case. The cause of PEM in the region was not determined, but the results suggest that in some cases sodium chloride intoxication/water deprivation could play a role in the etiology of the disease. PEM represents $4.78 \%$ of cattle disease diagnosed at the Pathology Laboratory of the Federal University of Mato Grosso do Sul.
\end{abstract}

INDEX TERMS: Polioencephalomalacia, cerebrocortical necrosis, cattle, thiamine, salt.

RESUMO: Trinta focos de polioencefalomalacia (PEM) foram diagnosticados no período de agosto de 1993 a outubro de 1997. Vinte e nove focos ocorreram no estado de Mato Grosso do Sul (MS) e um no estado de São Paulo (SP). Foram afetados bovinos de 4 a 84 meses de idade. A morbidade dos rebanhos afetados variou de $0,02 \%$ a $14,28 \%$ e a letalidade de $42,5 \%$ a $100 \%$. A doença não apresentou uma sazonalidade e ocorreu em vários municípios do MS. Em todos os focos estudados os animais afetados eram criados em regimes de criação

\footnotetext{
${ }^{1}$ Aceito para publicação em 16 de maio de 2000.

Parte da tese de mestrado do primeiro autor, Faculdade de Veterinária, Universidade Federal de Pelotas (UFPel), Pelotas, RS.

${ }^{2}$ Departamento de Clínica Médica Veterinária, Faculdade de Agronomia e Medicina Veterinária, Universidade Federal de Mato Grosso.

${ }^{3}$ Departamento de Medicina Veterinária, Universidade Federal de Mato Grosso do Sul, Cx. Postal 549, Campo Grande, MS 79070-900.

${ }^{4}$ Departamento de Patologia, Faculdade de Veterinária, Universidade Federal de Pelotas, 96010-900 Pelotas, RS.
}

extensiva, com exceção de um foco. Os sinais clínicos observados foram exclusivamente nervosos e a evolução dos casos variou de 12 horas a 4 dias. A maioria dos animais tratados com tiamina e dexametasona recuperou-se. Histologicamente, as lesões consistiam de necrose laminar do córtex cerebral. Adicionalmente em 2 casos observaram-se hemorragias submeningeanas e corticais, e em 9 casos presença de infiltrado de eosinófilos. A dosagem de sódio no líquor apresentou-se elevada em um caso. A etiologia da PEM não está esclarecida, porém em alguns casos a intoxicação por cloreto de sódio/privação de água pode estar envolvida na etiologia da enfermidade. A PEM representa $4,78 \%$ dos casos de enfermidades de bovinos diagnosticadas no Laboratório de Anatomia Patológica da UFMS. Com bases nos resultados, verifica-se a importância da enfermidade no diagnóstico diferencial de outras doenças com quadro clínico neurológico no MS, principalmente a raiva, a meningoencefalite por herpesvírus bovino tipo 5 (HVB-5) e o botulismo.

TERMOS DE INDEXAÇ̃̃O: Polioencefalomalacia, necrose cerebrocortical, bovino, tiamina, sal. 


\section{INTRODUÇÃO}

Polioencefalomalacia (PEM) ou necrose cerebrocortical (NCC) são termos utilizados para descrever o amolecimento ou necrose da substância cinzenta do cérebro (Jubb \& Huxtable 1993). Desde a sua primeira descrição em 1956 e durante os 25 anos subsequentes, a PEM em bovinos foi atribuída à deficiência de tiamina, associada à alta ingestão de grãos na ração (Radostits et al. 1994). Atualmente, acredita-se que a PEM não apresente mais uma etiologia específica, pois outros fatores têm sido associados a ocorrência da enfermidade (Radostits et al. 1994). $O$ alto consumo de enxofre na alimentação tem sido associado a PEM nos casos onde a concentração de tiamina no animal está normal (Raisbeck 1982, Hamlen et al. 1993, Olkowski 1997, Gould 1998). Em outras circunstâncias, alterações do manejo como privação de água e alimentos, em animais transportados, são incriminados como causa da PEM (Jubb \& Huxtable 1993, Radostits et al. 1994).

Este trabalho teve como objetivo determinar a epizootiologia, sinais clínicos e alterações anatomopatológicas dos surtos de polioencefalomalacia diagnosticados entre agosto de 1993 e outubro de 1997 pelo Laboratório de Anatomia Patológica da Universidade Federal do Mato Grosso do Sul (UFMS).

\section{MATERIAL E MÉTODOS}

Os dados epizootiológicos e sinais clínicos dos casos de PEM necropsiados no Hospital Veterinário da Universidade Federal do Mato Grosso do Sul (UFMS) foram colhidos através de entrevistas com proprietários ou médicos veterinários, que acompanharam os focos ocorridos entre agosto de 1993 e outubro de 1997. Os dados dos casos cujo material foi remetido a essa Instituição por veterinários de campo, foram obtidos das fichas clínicas enviadas com o material.

Os focos foram identificados por códigos de $\mathrm{F} 1$ a F30 e os animais provenientes dos focos por códigos C1 a C32 (Quadro 1). Dos 32 casos acompanhados, 9 foram acompanhados pelos autores, e 23 foram acompanhados por médicos veterinários de campo e o encéfalo remetido ao Laboratório de Patologia da UFMS.

Para a histopatologia, fragmentos de diversas vísceras, bem como o encéfalo foram fixados em formol $10 \%$, incluídos em parafina, cortados em seções de $6 \mathrm{~mm}$ e coradas pela hematoxilina-eosina.

A resposta clínica ao tratamento foi considerada como meio auxiliar para o diagnóstico. 0 tratamento, realizado em 24 bovinos de 7 diferentes focos, baseou-se na utilização de $10 \mathrm{mg}$ de tiamina por $\mathrm{kg}$ de peso vivo e $1 \mathrm{mg}$ de dexametasona por $\mathrm{kg}$ de peso vivo, diariamente por 2 a 3 dias ou até a recuperação total do animal.

Em todos os casos foram remetidos fragmentos de cérebro, cerebelo e medula espinhal para o diagnóstico diferencial de raiva no Laboratório de Virologia do Departamento de Inspeção e Defesa Agropecuária de Mato Grosso do Sul (IAGRO).

Em um foco (F28) foi realizada a dosagem de sódio no líquido cefalorraquidiano pelo método de espectrofotometria de chama.

\section{RESULTADOS}

Os principais dados epizootiológicos dos 30 focos de PEM apresentam-se no Quadro 2. Em relação ao sexo dos animais, a maioria dos casos ocorreram em fêmeas, sendo que de um
Quadro 1. Identificação dos focos e respectivos casos de polioencefalomalacia em bovinos no MS e SP, no período de agosto de 1993 a outubro de 1997

\begin{tabular}{ccll}
\hline $\mathrm{N}^{\circ}$ do foco & $\mathrm{N}^{\circ}$ do caso & Tipo de morte & Origem do material \\
\hline $1 \mathrm{~F}$ & $1 \mathrm{C}$ & Sacrificado & Necropsiado na UFMS \\
$2 \mathrm{~F}$ & $2 \mathrm{C}$ & Sacrificado & Enviado por veterinário \\
$3 \mathrm{~F}$ & $3 \mathrm{C}$ & Não informado & Enviado por veterinário \\
$4 \mathrm{~F}$ & $4 \mathrm{C}$ & Não informado & Enviado por veterinário \\
$5 \mathrm{~F}$ & $5 \mathrm{C}$ & Sacrificada & Necropsiado na UFMS \\
$6 \mathrm{~F}$ & $6 \mathrm{C}$ & Natural & Necropsiado na UFMS \\
$7 \mathrm{~F}$ & $7 \mathrm{C}$ & Sacrificado & Necropsiado na UFMS \\
$8 \mathrm{~F}$ & $8 \mathrm{C}$ & Sacrificado & Necropsiado na UFMS \\
$9 \mathrm{~F}$ & $9 \mathrm{C}$ & Sacrificado & Enviado por veterinário \\
$10 \mathrm{~F}$ & $10 \mathrm{C}$ & Não informado & Enviado por veterinário \\
$11 \mathrm{~F}$ & $11 \mathrm{C}$ & Não informado & Enviado por veterinário \\
$12 \mathrm{~F}$ & $12 \mathrm{C}$ & Não informado & Enviado por veterinário \\
$13 \mathrm{~F}$ & $13 \mathrm{C}$ & Não informado & Enviado por veterinário \\
$14 \mathrm{~F}$ & $14 \mathrm{C}$ & Natural & Enviado por veterinário \\
$15 \mathrm{~F}$ & $15 \mathrm{C}$ & Natural & Enviada por veterinário \\
$16 \mathrm{~F}$ & $16 \mathrm{C}$ & Não informado & Enviada por veterinário \\
& $17 \mathrm{C}$ & Sacrificado & Necropsiado na UFMS \\
$17 \mathrm{~F}$ & $18 \mathrm{C}$ & Sacrificado & Necropsiado na UFMS \\
& $19 \mathrm{C}$ & Sacrificado & Necropsiado na UFMS \\
$18 \mathrm{~F}$ & $20 \mathrm{C}$ & Natural & Necropsiado na UFMS \\
$19 \mathrm{~F}$ & $21 \mathrm{C}$ & Natural & Enviado por veterinário \\
$20 \mathrm{~F}$ & $22 \mathrm{C}$ & Natural & Enviado por veterinário \\
$21 \mathrm{~F}$ & $23 \mathrm{C}$ & Sacrificado & Enviado por veterinário \\
$22 \mathrm{~F}$ & $24 \mathrm{C}$ & Não informado & Enviado por veterinário \\
$23 \mathrm{~F}$ & $25 \mathrm{C}$ & Não informado & Enviado por veterinário \\
$24 \mathrm{~F}$ & $26 \mathrm{C}$ & Natural & Enviado por veterinário \\
$25 \mathrm{~F}$ & $27 \mathrm{C}$ & Natural & Enviado por veterinário \\
$26 \mathrm{~F}$ & $28 \mathrm{C}$ & Natural & Enviado por veterinário \\
$27 \mathrm{~F}$ & $29 \mathrm{C}$ & Natural & Enviado por veterinário \\
$28 \mathrm{~F}$ & $30 \mathrm{C}$ & Sacrificado & Enviado por veterinário \\
$29 \mathrm{~F}$ & $31 \mathrm{C}$ & Não informado & Enviado por veterinário \\
$30 \mathrm{~F}$ & $32 \mathrm{C}$ & Sacrificado & Enviado por veterinário \\
& & & \\
& & &
\end{tabular}

total de 32 casos, 21 eram fêmeas. Dos 29 focos observados no Mato Grosso do Sul, os municípios afetados foram Campo Grande (6 focos), Aquidauana (3), Anastácio (3), Rio Brilhante (2), Maracajú (2), Coxim (1), Água Clara (1), Três Lagoas (1), Anaurilândia (1), Naviraí (1), Bandeirantes (1), Jaraguarí (1), Rochedo (1), Terenos (1), Sidrolândia (1), Nova Alvorada (1), Guia Lopes (1) e Dourados (1). O foco F29 ocorreu no município de Araçatuba, São Paulo.

O sistema de criação dos animais em todos os focos era extensivo, exceto no foco F29 onde os animais eram confinados. As pastagens eram predominantemente do gênero Brachiaria spp, sendo utilizado Pennisetum americanum (milheto) no foco F22 e resteva de arroz no foco F28. A administração de suplemento mineral ocorreu em 10 focos ( $\mathrm{F} 1$, F2, F6, F9, F13, F17, F19, 28, F29 e F30). Em dois focos a enfermidade ocorreu em animais que estavam sendo comercializados em leilões (F6 e F7) e no foco F30 ocorreu a restrição de sal mineral por alguns dias seguido de acesso 3 dias antes do início da enfermidade.

Dos 32 animais necropsiados, 25 eram da raça Nelore e 6 mestiço Nelore, e em 1 caso a raça não foi informada. Os 32 casos de PEM no período deste estudo representam 4,76\% dos 671 casos de várias enfermidades diagnosticados no La- 
Quadro 2. Dados epizootiológicos dos focos de PEM no período de agosto de 1993 a outubro de 1997 em MS e SP

\begin{tabular}{|c|c|c|c|c|c|c|c|c|}
\hline Caso & $\operatorname{Sexo}^{a}$ & Mês & $\begin{array}{c}\text { Total de } \\
\text { animais }^{b}\end{array}$ & $\begin{array}{c}\text { Doentes } \\
n^{\circ}(\%)\end{array}$ & $\begin{array}{c}\text { Mortos } \\
n^{\circ}(\%)\end{array}$ & $\begin{array}{l}\text { Idade } \\
\text { (meses) }\end{array}$ & $\begin{array}{c}\text { Evolução } \\
\text { (dias) }\end{array}$ & Município \\
\hline 1 & M & mai./94 & 60 & $4(6,66)$ & $4(6,66)$ & 48 & 4 & Jaraguari \\
\hline 2 & $\mathrm{~F}$ & jun./94 & $\mathrm{NI}$ & $\mathrm{NI}$ & $\mathrm{NI}$ & 42 & $\mathrm{NI}$ & Coxim \\
\hline 3 & M & jun./94 & 350 & $3(0,86)$ & $3(0,86)$ & 24 & 1 & Sidrolândia \\
\hline 4 & $\mathrm{~F}$ & jun./94 & $\mathrm{NI}$ & NI & $\mathrm{NI}$ & 60 & $\mathrm{NI}$ & Três Lagoas \\
\hline 5 & M & jun./94 & 400 & $2(0,5)$ & $2(0,5)$ & 4 & 3 & Aquidauana \\
\hline 6 & $\mathrm{~F}$ & ago./94 & 140 & $20(14,28)$ & $19(13,57)$ & 18 & 0.5 & Maracajú \\
\hline 7 & M & set./94 & $\mathrm{NI}$ & 2 & 1 & 9 & 0.5 & Campo Grande \\
\hline 8 & $\mathrm{~F}$ & nov./94 & $\mathrm{NI}$ & 8 & 1 & 30 & 4 & Campo Grande \\
\hline 9 & $\mathrm{~F}$ & dez./94 & 2000 & $3(0,15)$ & $2(0,10)$ & 48 & 1 & Nova Alvorada do Sul \\
\hline 10 & $\mathrm{~F}$ & jan./95 & $\mathrm{NI}$ & $\mathrm{NI}$ & $\mathrm{NI}$ & 24 & 3 & Campo Grande \\
\hline 11 & $\mathrm{~F}$ & abr./95 & 110 & 10 & $\mathrm{NI}$ & 30 & $\mathrm{NI}$ & Campo Grande \\
\hline 12 & $\mathrm{~F}$ & set./95 & $\mathrm{NI}$ & $\mathrm{NI}$ & $\mathrm{NI}$ & 17 & $\mathrm{NI}$ & Naviraí \\
\hline 13 & $\mathrm{~F}$ & fev./96 & 800 & $10(1,25)$ & $9(1,12)$ & 30 & $\mathrm{NI}$ & Anaurilândia \\
\hline 14 & $\mathrm{~F}$ & mar./96 & 103 & $1(0,97)$ & $1(0,97)$ & 36 & 1.5 & Aquidauana \\
\hline 15 & M & mar./96 & 120 & $1(0,83)$ & $1(0,83)$ & 24 & 2 & Anastácio \\
\hline $16^{c}$ & $\mathrm{~F}$ & mar./96 & $\mathrm{NI}$ & 1 & 1 & 24 & 4 & Campo Grande \\
\hline $17^{\mathrm{c}}$ & $\mathrm{F}$ & abr./96 & 200 & $16(8)$ & $13(6,5)$ & 12 & 1 & Campo Grande \\
\hline $18^{\mathrm{d}}$ & $\mathrm{F}$ & abr./96 & 200 & $16(8)$ & $13(6,5)$ & 12 & $\mathrm{NI}$ & Campo Grande \\
\hline $19^{d}$ & $\mathrm{~F}$ & abr./96 & 200 & $16(8)$ & $13(6,5)$ & 12 & 4 & Campo Grande \\
\hline 20 & $\mathrm{~F}$ & mai./96 & 200 & $5(2,5)$ & $5(2,5)$ & 36 & 1 & Terenos \\
\hline 21 & $\mathrm{~F}$ & jun./96 & $\mathrm{NI}$ & $\mathrm{NI}$ & $\mathrm{NI}$ & 84 & 2 & Água Clara \\
\hline 22 & M & ago./96 & $\mathrm{NI}$ & 1 & 1 & 18 & 1 & Rio Brilhante \\
\hline 23 & $\mathrm{~F}$ & set./96 & 241 & $7(2,9)$ & $3(1,24)$ & 72 & $\mathrm{NI}$ & Maracaju \\
\hline 24 & $\mathrm{~F}$ & jan./97 & 150 & $2(1,33)$ & $2(1,33)$ & 20 & 3 & Bandeirantes \\
\hline 25 & M & mar./97 & 300 & $1(0,33)$ & $1(0,33)$ & 18 & 4 & Aquidauana \\
\hline 26 & $\mathrm{~F}$ & mar./97 & 1169 & $1(0,08)$ & $1(0,08)$ & 48 & 4 & Guia Lopes da Laguna \\
\hline 27 & $\mathrm{~F}$ & mar./97 & 4500 & $1(0,02)$ & $1(0,02)$ & 60 & 2 & Anastácio \\
\hline 28 & $\mathrm{~F}$ & abr./97 & 160 & $1(0,62)$ & $1(0,62)$ & 36 & 2 & Anastácio \\
\hline 29 & $\mathrm{~F}$ & mai./97 & 3300 & $2(0,06)$ & $2(0,06)$ & $\mathrm{NI}$ & $\mathrm{NI}$ & Rio Brilhante \\
\hline 30 & M & ago./97 & 250 & $2(0,8$ & $2(0,8)$ & 14 & $\mathrm{NI}$ & Dourados \\
\hline 31 & M & out./97 & 5000 & $1(0,02)$ & $1(0,02)$ & 36 & $\mathrm{NI}$ & Araçatuba \\
\hline 32 & $\mathrm{~F}$ & out./97 & 1750 & $1(0,06)$ & $1(0,06)$ & 72 & $\mathrm{NI}$ & Rochedo \\
\hline
\end{tabular}

Quadro 3. Sinais clínicos em ordem de frequiência observada nos casos ${ }^{\mathrm{a}}$ de PEM em bovinos, durante o período de agosto de 1993 a outubro de 1997

\begin{tabular}{lc}
\hline \multicolumn{1}{c}{ Sinais clínicos } & Freqüência \\
\hline Decúbito & 22 \\
Cegueira aparente & 16 \\
Opistótono & 15 \\
Andar cambaleante & 11 \\
Movimentos de pedalagem & 7 \\
Depressão & 4 \\
Anorexia & 4 \\
Nistagmo & 3 \\
Salivação excessiva & 3 \\
Rigidez dos membros & 3 \\
Tremor muscular & 2 \\
Paralisia flácida & 2 \\
Hipotermia & 2 \\
Afastamento do rebanho & 2 \\
Nervoso & 1 \\
Caquexia & 1 \\
Paralisia da língua & 1 \\
Miose & 1 \\
Taquicardia & 1 \\
Diminuição dos movimentos ruminais & 1 \\
Andar em círculo & 1 \\
Total de animais examinados & 31 \\
&
\end{tabular}

\footnotetext{
${ }^{\text {a }}$ Em um caso não foram informados sinais clínicos.
}

boratório de Anatomia Patológica da Universidade Federal de Mato Grosso do Sul.

Os sinais clínicos observados constam no Quadro 3. A evolução de 21 diferentes casos variou de 12 horas a 4 dias e nos demais não foram obtidas informações. A realização de tratamento em 14 casos de 8 diferentes focos apresentam-se na Figura 1. Nos focos, onde se realizou os tratamentos para PEM, observou-se a recuperação dos animais tratados, exceto no foco F1. Nos focos F7 e F17, os animais tratados apresentaram estabilização do quadro clínico.

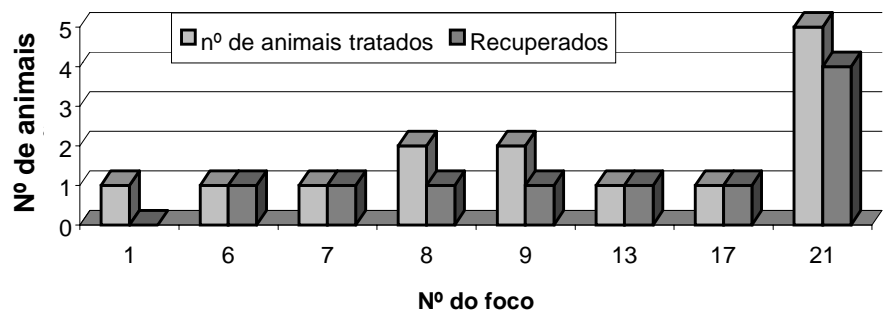

Figura 1. Ocorrência de tratamento e resposta clínica em 14 casos de PEM em 8 focos, durante o período de agosto de 1993 a outubro de 1997. 
Quadro 4. Alterações macroscópicas do SNC em 21 casos $^{\mathrm{a}}$ de PEM em bovinos no período de agosto de 1993 a outubro de 1997

\begin{tabular}{lc}
\hline \multicolumn{1}{c}{ Achados de Necropsia } & Freqüência \\
\hline Sem alterações significativas & 9 \\
Congestão & 7 \\
Achatamento das circunvoluções & 6 \\
Focos hemorrágicos & 3 \\
Deslocamento caudal & 2 \\
Amolecimento & 2
\end{tabular}

aEm 11 casos não foram informados as alterações de necropsia.

Quadro 5. Alterações histológicas encontradas nos casos de PEM em bovinos no período de agosto de 1993 a outubro de 1997

\begin{tabular}{cccccc}
\hline Caso & $\begin{array}{c}\text { Necrose } \\
\text { neuronal }\end{array}$ & $\begin{array}{c}\text { Proliferação } \\
\text { de vasos }\end{array}$ & Hemorragia Gliose & $\begin{array}{c}\text { Células Eosinófilos } \\
\text { Gitter }\end{array}$ \\
\hline
\end{tabular}

$+++\frac{10}{+1+}$

$\begin{array}{cc}+++^{\mathrm{a}} & ++ \\ + & + \\ + & + \\ +++ & + \\ +++ & ++ \\ + & ++ \\ +++ & ++ \\ ++ & ++ \\ + & + \\ +++ & +++ \\ ++ & ++ \\ + & + \\ +++ & ++ \\ +++ & ++ \\ ++ & ++ \\ + & ++ \\ + & + \\ ++ & + \\ +++ & +++ \\ +++ & ++ \\ ++ & + \\ +++ & +++ \\ + & + \\ +++ & +++ \\ +++ & ++ \\ ++ & + \\ ++ & ++ \\ ++ & ++ \\ ++ & +++ \\ +++ & ++ \\ ++ & ++ \\ +++ & +++ \\ & +\end{array}$

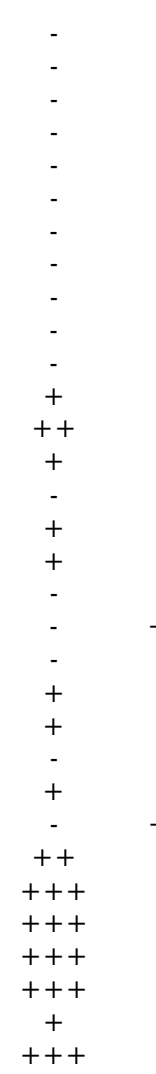

$\begin{array}{cc}+ & ++ \\ + & + \\ - & + \\ + & +++ \\ + & \\ ++ & + \\ ++ & +++ \\ + & + \\ + & + \\ ++ & +++ \\ ++ & +++ \\ + & + \\ ++ & +++ \\ ++ & ++ \\ + & ++ \\ ++ & + \\ ++ & + \\ + & ++ \\ +++ & +++ \\ ++ & ++ \\ ++ & ++ \\ ++ & ++ \\ ++ & - \\ ++ & +++ \\ +++ & +++ \\ + & ++ \\ + & +++ \\ ++ & ++ \\ ++ & ++ \\ ++ & ++ \\ ++ & ++ \\ ++ & +++ \\ & +\end{array}$

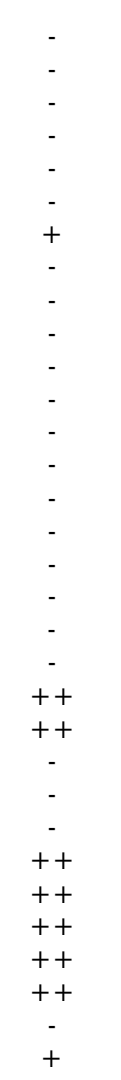

a - Ausente, + discreto, ++ moderado, +++ severo.

Na maioria dos casos os achados de necropsia eram mínimos ou não havia alterações, conforme Quadro 4 . Em um animal (C19) o cérebro apresentava áreas de cavitações no córtex cerebral e diminuição da densidade do cérebro constatada pela flutuação no formol a $10 \%$. Não foram observadas alterações nos demais órgãos.

As alterações histológicas dos 32 casos diagnosticados restringiam-se ao sistema nervoso central e encontram-se no Quadro 5. Na maioria dos casos, foram discreta a moderada necrose laminar dos neurônios do córtex cerebral, caracteri- zado por aumento dos espaços perineuronais, e aumento da eosinofilia do citoplasma neuronal com picnose. Foram observados, também, proliferação dos vasos sanguiíneos com células endoteliais tumefeitas e de núcleos arredondados nas áreas de necrose, infiltração de células inflamatórias mononucleares e presença de células Gitter. A necrose apresentava-se principalmente nos sulcos das circunvoluções, nas lâminas profundas e média das camadas corticais de neurônios. Em 9 casos ( C7, C21, C22, C26, C27, C28, C29, C30 e C32), além das lesões anteriormente descritas, observou-se discreta a moderada infiltração de eosinófilos principalmente nos espaços submeningeanos e perivasculares do córtex cerebral, e em alguns casos na neurópila, associados a hemorragia moderada a severa.

O nível de sódio do líquido cefalorraquidiano no caso C30 apresentava-se elevado, $163 \mathrm{meq} / \mathrm{l}$.

\section{DISCUSSÃO}

O diagnóstico da PEM foi realizado com base nas alterações macroscópicas e microscópicas no SNC semelhantes às descritas por outros autores (Jensen et al. 1956, Jubb \& Huxtable 1993, Summers et al. 1995). A resposta ao tratamento com tiamina e antiinflamatórios corticoesteróides em alguns casos foi considerada como um auxílio no diagnóstico (Radostits et al. 1994).

A enfermidade não apresentou um caráter sazonal, sendo que os focos ocorreram em todos os meses do ano. Este fato também foi observado por Gabbedy \& Richards (1977) em 14 casos estudados na Austrália. Nos EUA, Jensen et al. (1956) descrevera a ocorrência de PEM com dois picos de incidência; o primeiro no mês de janeiro em animais sob regime de confinamento e o segundo no mês de julho em animais a pasto. Na Grã Bretanha, os surtos ocorrem nos meses de novembro a março, correspondente ao inverno (Terlecki \& MarksoN 1959). A ocorrência sazonal desta enfermidade deve-se principalmente ao manejo alimentar adotado nestes países (Smith 1996). No MS, inicialmente Purisco (1982) descreveu uma maior incidência nos meses de junho a setembro, correspondente ao inverno (período de seca) em 7 casos estudados, porém Riet-Correa (1984), incluindo mais 13 casos ao estudo anterior, não observou a mesma sazonalidade.

Em relação a idade dos animais afetados observou-se grande variação (4 meses a 7 anos de idade), sendo a maior incidência em animais com idade igual ou superior a 25 meses (19 dos 30 focos). Purisco (1982) e Riet-Correa (1984) também assinalam o mesmo fato. Em outros países, entretanto, isto parece ser pouco comum, sendo a variação da idade de 6 a 18 meses, e o pico de incidência entre 9 a 12 meses (Radostitts et al. 1994, Jensen et al. 1956, Terlecki \& Markson 1959, Summers et al. 1995, Carrillo et al. 1976). Em alguns casos, nos quais a PEM é associada à ingestão de grandes quantidades de enxofre, a idade dos animais varia de acordo com a exposição a este elemento, podendo ocorrer tanto em animais jovens quanto adultos (Hamlen et al. 1993, Jeffrey et al. 1994, Harries 1987, Raisbeck 1982). Isto também obser- 
va-se nos casos de PEM associada à intoxicação por sal/privação de água (Lindley 1977, Trueman \& Claugue 1978, Pearson \& Kallfelz 1982).

A distribuição geográfica dos focos de PEM no Mato Grosso do Sul ocorreu principalmente nos municípios vizinhos ou próximos a Campo Grande, o que provavelmente deve-se à proximidade com o Laboratório de Anatomia Patológica Veterinária da UFMS. Num estudo sobre meningoencefalite em bovinos no MS causada por Herpesvírus bovino tipo 5, Salvador et al. (1998) observaram comportamento similar.

A taxa de morbidade nos focos estudados apresentou grande variação (de $0,02 \%$ a $14 \%$ ), demostrando que a enfermidade ocorre tanto na forma de surtos como em casos esporádicos. Os maiores índices de morbidade ocorreram em animais transportados que estavam sendo leiloados (F6). Em outros relatos da enfermidade a taxa de morbidade foi extremamente baixa (Gabbedy \& Richards 1977, Ferreira et al. 1986, Moro et al. 1994, Purisco 1982), podendo ocorrer em formas de surtos, principalmente nos casos de PEM associados a altas doses de enxofre e casos de intoxicação por sal (Padovan 1980). Na maioria dos focos estudados, a enfermidade ocorreu de forma esporádica, sendo que em 13 focos a morbidade foi igual ou menor a $1 \%$, e em apenas 4 focos a enfermidade apresentou índices de morbidade maiores que $6 \%$.

A mortalidade apresentou os mesmos valores das taxas de morbidade, exceto nos focos que realizou-se tratamento precoce dos animais, nesses casos a taxa de mortalidade foi menor. A letalidade apresentou grande variação entre os fo$\cos (48,5 \%$ a $100 \%)$. Deve-se salientar, entretanto, que nos focos em que os animais foram tratados, a taxa de letalidade apresentou-se menor que $100 \%$, exceto no foco F1. Neste caso, a não resposta ao tratamento possivelmente seja conseqüiência da instituição tardia do mesmo, pois a resposta ao tratamento é eficaz somente quando feito algumas horas após o início da enfermidade (Smith 1996, Radostits et al. 1994).

Os animais afetados na maioria eram da raça Nelore (25 casos) ou mestiços Nelore (6 casos), provavelmente devido ao maior número de cabeças desta raça no estado do MS. Segundo Jensen et al. (1956) a maior ocorrência da enfermidade na raça Hereford em seu estudo deve-se também à predominância da raça na região. Em bovinos, a predisposição racial parece não interferir na incidência da enfermidade.

As fêmeas foram mais afetadas que os machos, devido a maioria das propriedades serem de cria. Este fato já foi descrito por Purisco (1982) no estado do MS e Jensen et al. (1956) nos EUA, entretanto outros autores não relatam uma maior ocorrência da enfermidade em um ou outro sexo (Terlecki \&Markson 1961, Radostits et al. 1994, Smith 1996).

Em todos os focos diagnosticados os animais eram criados de forma extensiva, com exceção de um foco (F29). A ocorrência em animais em criações extensivas é pouco freqüente em outros países (Radostits et al. 1994, TerleckI \& Markson 1961, McGuirk 1987). Jensen et al. (1956) descrevem a ocorrência da enfermidade em animais a campo 5 a 10 dias após trocarem de um pasto ruim para um luxuriante, entretanto, outros autores associam casos de PEM a pastos contaminados com plantas que contêm tiaminases do tipo I como a Marsilea drummondii (Pritchard \& Eggleston 1978), Pteridium aquilinum e Equisetum arvense (Radostits et al. 1994) ou acumuladoras de enxofre como a Kochia scoparia (Dickie et al. 1979, Dickie \& Berryman 1979). Nenhuma dessas condições foram observada nas propriedades acometidas neste estudo.

A análise epizootiológica deste estudo encontra-se prejudicada, em muitos casos pela falta de informações mais detalhadas. $O$ sistema de criação extensivo, predominante no estado, com grande número de animais em extensas áreas de pastejo, associada à distância do centro de diagnóstico, dificultam o acompanhamento completo dos surtos e a possível ocorrência em anos posteriores. Por isso, é provável que os dados epizootiológicos como morbidade, mortalidade e letalidade não sejam precisos, uma vez que a coleta dos dados foi realizada durante o surto, muitas vezes não sendo possível o acompanhamento posterior. A resposta ao tratamento nos casos diagnosticados ocasiona uma subnotificação, por isso provavelmente não se observam focos da enfermidade em anos repetidos na mesma propriedade, uma vez que qualquer animal que apresente sintomatologia nervosa é tratado prontamente com doses de tiamina e antiinflamatórios corticoesteróides (dexametasona) recomendados para a PEM.

Os sinais clínicos e a evolução são semelhantes aos descritos em outros surtos de PEM( Jensen et al. 1956, Terlecki \& Markson 1959, Smith 1996). Em 2 casos tratados tardiamente, os animais não apresentaram melhora, porém estabilizouse o quadro clínico, com os animais permanecendo cegos, com diminuição do apetite, alheios ao ambiente e com mau desenvolvimento corporal, sendo um dos animais sacrificado após 40 dias. Em um estudo em Minas Gerais, observouse também a estabilização do quadro clínico após o tratamento, sendo o animal sacrificado 49 dias após o início dos sinais clínicos (Ferreira et al. 1986). Nos casos relatados por outros autores a enfermidade apresentou um comportamento similar, com evolução de algumas horas até vários dias, tanto em casos associados a deficiência de tiamina quanto nos associados a alta ingestão de enxofre e intoxicação por sal/privação por água (Jensen et al. 1956, TerleckI \& Markson 1961, Dickie et al. 1979, Jeffrey et al. 1994, Padovan 1980, Lindley 1977).

Os achados de necropsia no sistema nervoso central estão de acordo aos descritos em outros relatos da enfermidade (Jensen et al. 1956, Terlecki \& Markson 1961, Purisco 1982, Ferreira et al. 1986, Moro et al. 1994). Em 9 casos não observaram-se alterações macroscópicas significativas. No entanto, nas necropsias realizadas por técnicos do laboratório aparentemente em todos os animais foram observadas lesões macroscópicas no SNC. Em 1 caso de um animal com evolução prolongada, o cérebro apresentava-se descorticado e flutuava quando posto no formol a $10 \%$. Jensen et al. (1956) descrevem o desaparecimento do córtex, associados aos casos de recuperação espontânea ou casos crônicos, entretanto não relata este último fato.

Hemorragia severa, submeningeana e no córtex subjacente (C29), é semelhante a observada nas encefalopatias em humanos associadas a intoxicação acidental por $\mathrm{NaCl}$ em crian- 
ças lactentes (Elton et al. 1963) e na intoxicação experimental por sal em gatos (Finberg et al. 1959, Luttrell et al. 1959). Entretanto este fato não foi observado nos casos de intoxicação por sal espontânea em bovinos (Trueman \& Claugue1978, Padovan 1980). Jensen et al. (1956) descrevem a baixa ocorrência de hemorragias em seu estudo, onde somente 6 casos de um total de 98 com diagnóstico de PEM apresentaram hemorragia.

Histologicamente, as alterações foram, na maioria dos casos, semelhantes às descritas por Jensen et al. (1956), Terleckl \& Markson (1961) e Purisco, (1982). Em nove casos, entretanto, constataram-se, além das lesões de necrose laminar cortical, presença de discreto a moderado infiltrado de eosinófilos nos espaços submeningeanos, perivasculares e na neurópila do córtex, associadas em alguns casos (C26, C27, C28, C29, C30 e C32) a hemorragia severa a moderada. A infiltração de eosinófilos é considerada uma alteração patognomônica da intoxicação por sal em suínos, e de ocorrência variável experimentalmente em frangos, perus, coelhos e faisões. Em casos de intoxicação por sal em bovinos (Trueman \& Claugue 1978, Padovan 1980) e outros ruminantes a presença desta lesão não é registrada. Segundo Carlton \& MacGavin (1995), o infiltrado de eosinófilos em casos de intoxicação por sal em suínos ocorre principalmente na fase aguda, sendo estes substituídos gradativamente por macrófagos após 24 horas, sendo difícil a detecção após este período. Este fato provavelmente possa explicar a não observação destas células em outros casos de PEM associada a intoxicação por sal, nos casos em que a evolução dos sinais clínicos for superior a 24 horas.

Os níveis de sódio aumentado no soro sangüíneo e líquido cefalorraquidiano são descritas nos casos de intoxicação por sal/privação de água em várias espécies como suínos (Osweiler \& Hurd 1974), ovinos (Scarratt et al. 1985) e bovinos (Pearson \& Kallfelz 1982, Padovan 1980, McGuirck 1987). No caso F28 ocorreu aumento dos níveis de sódio no líquido cefalorraquidiano $(163 \mathrm{mEq} / \mathrm{l})$, sendo níveis superiores a $160 \mathrm{mEq} / \mathrm{l}$ considerados sugestivos de intoxicação por sal em bovinos (Smith 1996). Associada a este fato, a presença de infiltrado de eosinófilos, neste caso, é similar aos casos de intoxicação em suínos.

A etiologia dos casos de PEM descritos no MS e SP não está totalmente esclarecida. A ocorrência de resposta ao tratamento com tiamina, na maioria dos casos estudados, não é conclusivo de que o problema trata-se de distúrbio do metabolismo de tiamina, pois em casos de intoxicação por enxofre (Olkowski 1997, Gould 1998) e chumbo (Smith1996) também ocorre resposta ao tratamento.

A ocorrência da PEM em bovinos para arremate enviados a leilões (focos F6 e F8) e em um rebanho no qual tinha sido suspenso a administração de sal mineral e posteriormente reiniciada, sugerem que a intoxicação por cloreto de sódio/ privação por água poderiam ser responsáveis, ou ter um papel predisponente na PEM. A elevada concentração de Na no líquor de um animal e a presença de eosinófilos em nove caso de PEM reforçam também essa possibilidade.

Uma vez que a etiopatogenia não está devidamente esclarecida, as medidas de controle e prevenção ficam prejudicadas.

\section{REFERÊNCIAS}

Carlton W.W. \& MacGavin M.D. 1995. Thomson's Special Veterinary Pathology. 2nd ed. Mosby, London. 654p.

Carrillo B.J., Casaro A. \& Villar J. 1976. Polioencefalomalacia en bovinos. Anais XV Congr. Bras. Med. Vet. Rio de Janeiro, RJ. (Resumo)

Dickie C.W. \& Berryman J.R. 1979. Polioencephalomalacia and phothosensitization associated with Kochia scoparia consumption in range cattle. J. Am. Vet. Med. Assoc. 175(5):463-465.

Dickie C.W., Nelson R.J., Frazee D.G, Krugman L.D. \& Bronner E. 1979. Polioencephalomalacia in range cattle. J. Am. Vet. Med. Assoc. 175(5):460462.

Elton N.W., Elton W.J. \& Nazareno J.P. 1963. Pathology of acute salt poisoning in infants. Am. J. Clin. Path. 39:252-264.

Ferreira F.A., Coelho H.E. \& Bastos J.E.D. 1986. Polioencefalomalacia em bovinos no Estado de Minas Gerais. Arq. Bras. Med. Vet. Zootec. 38(5):693-700.

Finberg L., Luttell C. \& Reed H. 1959. Pathogenesis of lesions in the nervous system in hipernatremic states. II. Experimental studies of gross anatomic changes and alterations of chemical composition of the tissues. Pediatrics 23:46-53.

Gabbedy B.J. \& Richards R.B. 1977. Polioencephalomalacia of sheep and cattle. Aust. Vet. J. 53:36-38.

Gould D.H. 1998. Polioencephalomalacia. J. Anim. Sci. 76: 309-314.

Hamlen H., Clark E. \& Janzen E. 1993. Polioencephalomalacia in cattle consuming water with elevated sodium sulfate levels: a herd investigation. Can. Vet. J. 34:153-158.

Harries W.M. 1987. Polioencephalomalacia in feedlot cattle drinking water high in sodium sulfate. Can. Vet. J. 28: 717.

Jeffrey M., Duff J.P., Higgins R.J., Simpson V.R., Jackman R., Jones T.O., Mechie S.C. \& Livesey C. T. 1994. Poliencephalomalcia associated with the ingestion of ammonium sulphate by sheep and cattle. Vet. Rec. 134:343-348.

Jensen R., Griner L.A. \& Adams O.R. 1956. Polioencephalomalacia of cattle and sheep. J. Am. Vet. Med. Assoc. 129:311-321.

Jubb K.V.F. \& Huxtable C.R. 1993. The nervous system, p. 267-439. In: Jubb KVF, Kennedy P.C. \& Palmer N. (ed) Pathology of Domestic Animals. Vol.1. 4th ed. Academic Press, San Diego. 780p.

Lindley W.H. 1977. Water deprivation in cattle. J. Am. Vet. Assoc. 171:439440.

Luttrell C.N., Finberg L. \& Drawdy L.P. 1959. Hemorragic encephalopathy induced by hypernatremia. II. Experimental observations on hyperosmolarity in cats. Arch. Neurol. 1:153-160.

McGuirk S.M. 1987. Polioencephalomalacia. Veterinary Clinics of North America: Food Animals Practice 3:107-117.

Moro L., Nogueira R.H.G., Carvalho A.U. \& Marques D.C. 1994. Relato de três casos de poliencefalomalacia em bovinos. Arq. Bras. Med. Zootec. 46(4):409416.

Osweiler G.D. \& Hurd J.W. 1974. Determination of sodium content in serum and cerbrospinal fluid as an adjunct to diagnosis of water deprivation in swine. J. Am. Vet. Med. Assoc. 165:165-167.

Olkowski A.A. 1997. Neurotoxicity and secondary metabolic problems associated with low to moderate levels of exposure to excess dietary sulphur in ruminants: a review. Vet. Human Toxicol 39(6):355-360.

Padovan D. 1980. Polioencefalomalacia associated with water deprivation. Cornell Vet. 70:153-159.

Pearson E.G. \& Kallfelz F.A. 1982. A case of presuntive salt poisoning (water deprivation) in veal calves. Cornell Vet. 72:142-149.

Pritchard D. \& Eggleston G.W. 1978. Nardoo fern and polioencephlomalacia. Aust. Vet. J. 54:204-205.

Purisco, E. 1982. Ocorrência de poliencefalomalacia em bovinos no Mato 
Grosso do Sul. Monografia apresentada como requisito para obtenção do grau de especialista em Diagnóstico Médico Veterinário. Universidade Federal de Mato Grosso do Sul, Campo Grande, MS, p.25.

Radostits O.M, Blood D.C \& Gay C.C. 1994. Veterinary Medicine. 8th ed. Baillière Tindall, London. $1763 \mathrm{p}$.

Raisbeck M.F. 1982. Is polioencephalomalacia associated with high-sulfate diets? J. Am. Vet. Med. Assoc. 180(11):1303-1305.

Riet-Correa F. 1984. Avaliação econômica e epidemiológica dos problemas sanitários do rebanhos de Mato Grosso do Sul. Relatório. 40 p.

Salvador S.C, Lemos R.A.A., Riet-Correa F., Roehe P.M. \& Osório A.L.A.R. 1998. Meningoencefalite em bovinos causada por herpesvírus bovino-5 no Mato Grosso do Sul e São Paulo. Pesq. Vet. Bras. 18(2): 76-83.
Scarratt W.K., Collins T.J. \& Sponenberg P. 1985. Water deprivation-sodium chloride intoxication in a group of feeder lambs. J. Am. Vet. Med. Assoc. 186(9):977-978.

Smith, B.P. 1996. Large Animal Internal Medicine. 2nd ed. Mosby, London. 1738p.

Summers B.A., Cummings J.F. \& Lahunta A. 1995. Veterinary Neuropathology. Mosby, London. 527p.

Terlecki S. \& Markson L.M. 1959. Cerebrocortical necrosis. Vet. Rec. 71:508. Terlecki S. \& Markson L.M. 1961. Cerebrocortical necrosis in cattle and sheep. Vet. Rec. 73(2):23-27.

Trueman K.F. \& Claugue D.C. 1978. Sodium chloride poisoning in cattle. Aust. Vet. J. 54:89-91. 